\title{
Rare earths separation from fluorescent lamp wastes using ionic liquids as extractant agents
}

\author{
S. Pavón ${ }^{a}$, A. Fortuny ${ }^{a}$, M.T. Coll ${ }^{b}$, A.M. Sastre ${ }^{c}$. \\ ${ }^{a}$ Chemical Engineering Department, EPSEVG, Universitat Politècnica de Catalunya, Víctor Balaguer 1, \\ 08800 Vilanova i la Geltrú, Spain.
}

${ }^{b}$ Agri-Food Engineering and Biotechnology Department, ESAB, Universitat Politècnica de Catalunya, Esteve Terrades 8, 08860 Castelldefels, Spain

${ }^{C}$ Chemical Engineering Department, ETSEIB, Universitat Politècnica de Catalunya, Diagonal 647, 08028 Barcelona, Spain

\begin{abstract}
Processing of end-of-life products has become essential in the rare earth elements (REEs) recovery field because the demand for these metals has increased over the last years due to their intensive use in advanced technologies. Fluorescent lamp wastes are considered one of the most interesting end-of-life products for investigation due to their high REEs content, mainly yttrium and europium. As a result, red phosphors $\left(\mathrm{Y}_{2} \mathrm{O}_{3}: \mathrm{Eu}^{3+}-\mathrm{YOX}\right)$ have been chosen for evaluating their REEs' recovery potential. The REEs from a YOX reach liquor, coming from a soft leaching process have been precipitated adding oxalic acid and calcined to get the REEs in oxide form. Cyanex 572, D2EHPA and the ionic liquids, Primene 81R.Cyanex $572 \mathrm{IL}$ and Primene 81R.D2EHPA IL, have been chosen to investigate the efficiency of REEs separation in chloride media. Yttrium, europium and cerium have been individually recovered by a four stages cross-flow solvent extraction process using the Primene 81R.D2EHPA IL and the Primene 81R. Cyanex $572 \mathrm{IL}$ as extractants. $\mathrm{Ce}(\mathrm{III}), \mathrm{Eu}(\mathrm{III})$ and $\mathrm{Y}(\mathrm{III})$ have been obtained at high purities $\geq 99.9 \% .4$ $\mathrm{mol} / \mathrm{L} \mathrm{HCl}$ has been used to recover the yttrium and the europium from the organic phases.
\end{abstract}

\section{Keywords}

REE separation; Ionic liquid; Solvent Extraction; Primene 81R.D2EHPA IL; Primene 81R.Cyanex 572 IL. 


\section{Introduction}

In recent years, the REEs group has been considered crucial in advanced technologies (such as phosphors, permanent magnets, batteries, lasers, etc.) because of their chemical properties. The continuous growing interest in electric and hybrid cars, fluorescent lamps, wind turbines, technologic devices and permanent magnets leads to an exponential increasing demand for REEs. As shown in the literature, the high fluctuations price, the grown usage, especially in the clean energy markets and their supply risk are the main reasons for declaring neodymium, terbium, dysprosium, yttrium and europium as critical metals (Hasegawa et al., 2018; Innocenzi et al., 2016). Developing strategies for recycling and recovering REEs from end-of-life products and waste streams is essential for the green technologies and supply stability and sustainability improvement. The highest consumptions of REEs, essentially yttrium and europium, are concentrated in the fluorescent lamps market. Due to the eradication of the traditional incandescent bulbs, the manufacture of the fluorescent lamps containing phosphors has increased in the last few years (Ippolito et al., 2017). This substitution allows a saving up to $€ 100$ over a product's lifetime which is around 20 years. Furthermore, fluorescent lamps, which produce an efficient use of the lighting energy, could save enough energy to power 11 million households for one year and avoid emissions of 12 million tonnes of $\mathrm{CO}_{2}$ in Europe (European Commission, 2009).

Fluorescent lamps contain mainly three different phosphors: red phosphors $\mathrm{Y}_{2} \mathrm{O}_{3}: \mathrm{Eu}^{3+}$ (YOX), blue phosphors $\mathrm{BaMgAl}_{10} \mathrm{O}_{17}: \mathrm{Eu}^{2+} \quad(\mathrm{BAM})$ and green phosphors $\mathrm{LaPO}_{4}: \mathrm{Ce}^{3+}, \mathrm{Tb}^{3+}$ (LAP), $(\mathrm{Gd}, \mathrm{Mg}) \mathrm{B}_{5} \mathrm{O}_{12}: \mathrm{Ce}^{3+}, \mathrm{Tb}^{3+}$ (CBT) and (Ce,Tb)MgAl ${ }_{11} \mathrm{O}_{19}$ (CAT) (Song et al., 2013). The REEs amount present in these three different phosphors is about 55,35 and $10 \mathrm{wt} \% \%$, respectively. As the most abundant representatives of REEs, the separation process of $Y(I I I)$ and $E u(I I I)$ has been investigated in this study by using halophosphate phosphors, rich in YOX phosphors.

Although the cationic commercial extractants such as Cyanex 572 (Cy572) or D2EHPA (di-(2ethylhexyl)phosphoric acid) have been studied in many investigations, they have also been evaluated in the current research as well as the ionic liquid extractants formed by Primene $81 \mathrm{R}$ (t-alkyl primary amine) along with them. Several reports on ionic liquids for REEs separation have appeared in recent literature (Prodius and Mudring, 2018; Su et al., 2018). However, they usually are formed by a cation from a quaternary ammonium or phosphonium salt and a conjugated base from an acidic cation exchanger. In 
this investigation, an innovative approach is presented by using a primary amine, such as Primene $81 \mathrm{R}$ for the formation of the ionic liquid because of its higher basicity compared to the secondary and tertiary amines (Borai et al., 2014).

Up to now, there are many separation and recovery processes for REEs. Nevertheless, solvent extraction (SX) is the chosen technique since a lot of literature studies depict a wide range of different extractants that can be used to selectively separate the REEs (Innocenzi et al., 2017; Tunsu et al., 2014). Different separation studies using ionic liquids were reported recently. A better $\mathrm{Nd} / \mathrm{Pr}$ separation factor was obtained with the addition of TBP in the binary mixture of Cyanex 272 and Alamine 336 (Liu et al., 2015). Padhan and Sarangi proposed Cyanex 272.Alamine $336 \mathrm{IL}$ as the best extractant to recover neodymium and praseodymium (Padhan and Sarangi, 2017). The Mishra and Devi investigation suggested the extraction mechanism for Cyphos IL 104. They concluded that three $\mathrm{H}^{+}$ions are involved to the aqueous phase making the solution acidic using D2EHPA, while an ion association is the extraction mechanism when Cyphos IL 104 is used. Although a higher extraction efficiency was observed in the Ce, La, Y and Eu extraction using Cyphos IL 104, the Y/Eu selectivity was higher using D2EHPA (Mishra and Devi, 2018). Belova et al. studied the REEs extraction in chloride and nitrate media using Aliquat 336.Cyanex $272 \mathrm{IL}$ in toluene (Belova et al., 2009). They noted that the distribution ratio were almost constant above $\mathrm{pH} 5$ and the extraction mechanism was depitcted as a binary extraction by (Eq.(1)):

$$
3 \overline{R_{4} N^{+} A^{-}}+M e^{3+}+3 \mathrm{Cl}^{-} \leftrightarrow \overline{M e A_{3} \cdot 3 R_{4} N^{+} \mathrm{Cl}^{-}}
$$

The separation of Th(IV) from several rare earths (III) such as La, Ce, Nd, Gd and Er was investigated using $\mathrm{N} 1923 /\left[\mathrm{C}_{8} \mathrm{mim}_{[}\left[\mathrm{PF}_{6}\right] \mathrm{IL}\right.$ by Yong Zuo et al (Zuo et al., 2008). A four-stage counter current extraction process was carried out by Coll et al. using a bench scale mixer-settler to separate $\mathrm{Co}(\mathrm{II})$ and $\mathrm{Ni}(\mathrm{II})$ by $20 \%$ of JMT·Cy272 IL (Coll et al., 2012). Although the technique used was not SX, García-Díaz et al. investigated the $\mathrm{In}(\mathrm{III})$ transport using $\mathrm{RNH}_{3}{ }^{+} \mathrm{HSO}_{4}{ }^{-} \mathrm{IL}$ by hollow fiber strip dispersion (García-Díaz et al., 2017). $80 \%$ of $\operatorname{In}(\mathrm{III})$ transport was achieved after $3 \mathrm{~h}$ using a feed at $\mathrm{pH} 2.0$ and $0.25 \mathrm{~mol} / \mathrm{L}$ of IL in Solvesso 100.

The amount of waste electrical and electronic equipment (WEEE) generated in Europe is about 12 million of tonnes per year and the forecast is expected to increase in the next years of at least $4 \%$ per annum (Tsamis and Coyne, 2015). According to data from the European Electronic Recycles Association, its 38 
members and over 100 subsidaries had a total of 2.2 million tonnes of WEEE treated per year. There are a small number of companies focusing on the refining and smelting of the rare earths and precious metals. To minimize the residuous amount and contibute to a green and circular economy, the legal framework of 2008 has been changed by the European Union introducing the following priority objectives for waste management in the EU: (1) reduce the waste generated amount, (2) maximise the recycling and the re-use, (3) limit the incineration to non-recyclable materials, (4) phase out landfilling to non-recyclable and non-recoverable waste (5) ensure the full implementation of the waste policy targets in all the EU Member States. In addition, the waste management domain represents one of the most important contributor to employment growth in the environmental economy as shown by the environmental goods and sevices accounts. Furthermore, banning the fluorescent lamps to LEDs (European Union, 2009) could cause an increase on the REEs wastes. The main approach of this research is the use of these waste products to overcome the overexploitation of the primary resources, which are not sustainable. The recycling of REEs from lamp phosphors can be carried out by: (1) direct re-use of these recycled lamps in new ones, (2) recycling the components of these phosphors using physicochemical separation methods to re-use in new lamps and (3) chemical attack to the fluorescent lamps to recover their REE content (Binnemans et al., 2013).

In this sense, recycling of REEs from the secondary resources like scraps or fluorescent lamp wastes should gain relevance. Considering that their main REEs content are yttrium and europium which are both critical REEs, a Ce/Eu/Y mixture has been investigated to reach the individual REEs separation. The aim of this research is to achieve their separation from leachates, using D2EHPA and Cy572 as cationic commercial extractants or Primene 81R·D2EHPA IL (P81R·D2EHPA IL) and Primene 81R·Cyanex 572 IL (P81R.Cy572 IL) as ionic liquid extractants. The first part of the study focused on the choice of the commercial cationic or ionic liquid extractants, taking into account their selectivity and their behaviour on the $\mathrm{Ce} / \mathrm{Eu} / \mathrm{Y}$ separation and the second part aims on the separation of the REEs from the Ce/Eu/Y mixture using the concentrations found in real fluorescent lamps wastes using IL's. 


\section{Experimental and methods}

\subsection{Reagents}

End-of-life fluorescent lamp waste as the main raw material in this investigation was obtained from Recyberica Ambiental S.L (Spain). Cyanex 572 and Primene 81R were supplied by Cytec Canada Industries and Dow Chemical, respectively and D2EHPA was provided by Sigma-Aldrich (Ref. 237825), and all of them were used as received. Kerosene (Ref. 607010) from Sigma-Aldrich as a diluent and hydrochloric acid as stripping agent were used. Detailed specifications of the extractants are summarized in Table 1.

Table 1. Physical properties of Cy572, P81R and D2EHPA.

\begin{tabular}{lllll}
\hline \multicolumn{1}{c}{ Commercial name } & $\begin{array}{c}\text { Content } \\
\%\end{array}$ & $\begin{array}{c}\text { Density } \\
\mathbf{k g} / \mathbf{m}^{3}\end{array}$ & $\begin{array}{c}\text { Viscosity }\left(\mathbf{2 5}^{\circ} \mathrm{C}\right) \\
\mathbf{m P a} \cdot \mathbf{s}\end{array}$ & $\begin{array}{c}\text { Av. Mol. Weight } \\
\mathbf{g} / \mathbf{m o l}\end{array}$ \\
\hline Cyanex 572 & $100^{\mathrm{a}}$ & $933^{\mathrm{a}}$ & $<50^{\mathrm{a}}$ & $310^{\mathrm{b}, \mathrm{c}}$ \\
Primene 81R & 100 & 860 & 2.58 & $191^{\mathrm{C}}$ \\
D2EHPA & $97^{\mathrm{e}}$ & $965^{\mathrm{e}}$ & & $332^{\mathrm{e}}$ \\
\hline
\end{tabular}

a (CYTEC Industries Inc., 2013).

${ }^{\mathrm{b}}$ As a monomer.

${ }^{\mathrm{C}}$ Experimental data by potentiometric titration in water/ethanol.

"Viscosity data by Rohm HA\&AS ("ROHM HA\&AS," 1961).

e (Sigma-Aldrich, 2002).

A procedure similar to the reported by Coll et al. was followed to prepare both ionic liquids (Coll et al., 2012). Stoichiometric quantities of two commercially available extractants P81R and D2EHPA or P81R and Cy572 were mixed in kerosene to prepare both ionic liquids, P81R·D2EHPA IL and P81R·Cy572 IL, as is shown in Eq. (2). Cationic extractants were considered in dimeric form.

$$
2 \overline{R N H_{2}}+\overline{(H A)}_{2} \leftrightarrow 2 \overline{R N H_{3}^{+} A^{-}}
$$

\subsection{Experimental procedure}

Fluorescent lamp wastes were treated in a first leaching, $\mathrm{L} 1$, with $\mathrm{HCl}$ of low concentration $(1 \mathrm{~mol} / \mathrm{L})$ for 10 min to separate non-ferrous impurities, mainly calcium. Then, the solid residue obtained from L1 stage underwent a second leaching process (L2) using high $\mathrm{HCl}$ concentration $(2 \mathrm{~mol} / \mathrm{L})$ for $2 \mathrm{~h}$ to obtain a liquor reach in REEs. After the acid treatments, the REEs oxalate precipitate was obtained by addition of oxalic acid $1 \mathrm{M}$. Then, the REEs oxalate precipitate was calcined at $600{ }^{\circ} \mathrm{C}$ for $1 \mathrm{~h}$ (Ippolito et al., 2017) to 
recover the metals in oxide form. REEs oxides were dissolved with $\mathrm{HCl} 2 \mathrm{~mol} / \mathrm{L}$ to obtain the work solution to carry out the YOX leachate separation process.

\subsubsection{Solvent extraction}

The preliminary solvent extraction experiments were carried out using an aqueous phase containing $1 \mathrm{~g} / \mathrm{L}$ of yttrium, europium and cerium in $4 \mathrm{~mol} / \mathrm{L} \mathrm{Cl}^{-}$medium. $10 \mathrm{~mL}$ of this aqueous phase were equilibrated with an equal volume of organic phase into a separatory funnel at room temperature $\left(20 \pm 2{ }^{\circ} \mathrm{C}\right)$ using a horizontal mechanical shaker (SBS Mechanical Shaker) at $140 \mathrm{rpm}$. Like done in previous kinetic experiments (Pavón et al., 2018), after 5 min the extraction equilibrium was achieved. Nevertheless, the shaking time for all the experiments was prolonged until $10 \mathrm{~min}$ to guarantee complete equilibration. After both phases were separated, the aqueous phase was taken out and put aside for metal concentration measurement. The loaded organic phases were stripped using $\mathrm{HCl} 4 \mathrm{~mol} / \mathrm{L}$. The experiments were carried out three times and the REEs concentration in the aqueous phase was determined by atomic emission spectrometry using a 4100 MP AES System (Agilent Technologies) with an analytical error $\leq 5 \%$.

Extraction efficiency $(\% E)$, stripping efficiency $(\% S)$, distribution ratio $(D)$ and separation factor $(\beta)$ were the parameters used to analyse the obtained results, and are defined in Eqs. (3)-(6):

$$
\begin{aligned}
& \% E=\frac{[M e]_{\text {ini }}-[\mathrm{Me}]_{\text {aq }}}{[\mathrm{Me}]_{\text {ini }}} \cdot 100 \\
& \% S=\frac{[\mathrm{Me}]_{\text {str }}}{[\mathrm{Me}]_{\text {org }}} \cdot 100 \\
& D_{M e}=\frac{[\mathrm{Me}]_{\text {org }}}{[\mathrm{Me}]_{\text {aq }}} \\
& \beta_{1,2}=\frac{D_{M e 1}}{D_{M e 2}}
\end{aligned}
$$

where $[\mathrm{Me}]_{\text {ini }}$ and $[\mathrm{Me}]_{\text {eq }}$ refer to the initial and the equilibrium REE concentration in the aqueous phase, $[\mathrm{Me}]_{s t r}$ is the equilibrium REE concentration in the stripping phase and $[\mathrm{Me}]_{\text {org }}$ is the REE concentration in the loaded organic phase obtained by mass balance. 


\subsection{Extraction mechanism}

The metal extraction mechanism was investigated to confirm the difference between the extraction process using cationic extractants such as Cy572 or D2EHPA, mechanism proposed in Eq. (7), and the ionic liquids such as P81R.Cy572 IL or P81R·D2EHPA IL (Eq. (8)). The equilibrium constants are written and shown in Eqs. (9)-(10) taking into account the distribution ratio D:

$$
\begin{aligned}
& M e^{3+}+3 \overline{(H A)_{2}} \stackrel{K_{1}}{\leftrightarrow} \overline{M e\left(H A_{2}\right)_{3}}+3 H^{+} \\
& 3 \overline{\mathrm{RNH}_{3}^{+} \mathrm{A}^{-}}+\mathrm{Me}^{3+}+3 \mathrm{Cl}^{-} \stackrel{\mathrm{K}_{2}}{\leftrightarrow} \overline{\mathrm{MeA}_{3} \cdot 3 \mathrm{RNH}_{3}^{+} \mathrm{Cl}^{-}} \\
& K_{1}=\frac{\left[M e\left(H A_{2}\right)_{3}\right] \cdot\left[H^{+}\right]^{3}}{\left[M e^{3+}\right] \cdot\left[\overline{(H A)_{2}}\right]^{3}}=\frac{D \cdot\left[H^{+}\right]^{3}}{\left[\overline{(H A)_{2}}\right]^{3}} \\
& K_{2}=\frac{\overline{\left[\mathrm{MeA}_{3} \cdot 3 \mathrm{RNH}_{3}^{+} \mathrm{Cl}^{-}\right]}}{\left[\mathrm{Me}^{3+}\right] \cdot\left[\mathrm{RNH}_{3}^{+} \mathrm{A}^{-}\right]^{3} \cdot\left[\mathrm{Cl}^{-}\right]^{3}}=\frac{D}{\left[\mathrm{RNH}_{3}^{+} \mathrm{A}^{-}\right]^{3} \cdot\left[\mathrm{Cl}^{-}\right]^{3}}
\end{aligned}
$$

Eqs. (11) and (12) were obtained by applying logarithms to Eqs. (9) and (10).

$$
\begin{aligned}
& \log D=\log K_{1}+3 \log \left[\overline{(H A)_{2}}\right]-3 \log \left[\mathrm{H}^{+}\right] \\
& \log D=\log K_{2}+3 \log \left[\overline{R N H_{3}^{+} A^{-}}\right]+3 \log \left[\mathrm{Cl}^{-}\right]
\end{aligned}
$$

A slope of 3 should be obtained plotting $\log D-3 \log \left[\overline{(H A)_{2}}\right]$ vs. $-\log \left[H^{+}\right]$, meaning that three protons are involved in the suggested cationic extraction process, according to the Eq. (7). However, protons are not involved in the proposed extraction mechanism using ionic liquids as shown in Eq. (8). Therefore, plotting $\mathrm{pH}_{\text {eq. }}$ vs. $\mathrm{pH}_{\text {initial }}$, a slope of 1 should be obtained.

\section{Results and discussion}

\subsection{REEs separation/extractability investigation}

\subsubsection{Effect of $\mathrm{pH}$}

Cy572, D2EHPA, P81R·Cy572 IL and P81R·D2EHPA IL were the chosen extractants to investigate their affinities for the REEs from YOX phosphors. The effect of the equilibrium $\mathrm{pH}$ on the extraction of cerium, europium and yttrium was investigated using an aqueous phase containing $1 \mathrm{~g} / \mathrm{L}$ of each REE in $4 \mathrm{~mol} / \mathrm{L}$ 
$\mathrm{Cl}^{-}$medium and $0.30 \mathrm{~mol} / \mathrm{L}$ of each extractant in the organic phase using a phase ratio (A:O) of $1: 1$. Since the $\mathrm{pH}$ measurements are not accurate under the highly acidic conditions studied, the equations have been written in hydrogen ion concentration terms.

As shown in Fig. 1, the REEs extraction tendency is the same regardless of each extractant used. Cy572 extracted at a higher pHs compared to D2EHPA, due to the strength of the complex formed with the REEs. Apart from this fact, the extraction yield order obtained was always $\mathrm{Y}(\mathrm{III})>\mathrm{Eu}(\mathrm{III})>\mathrm{Ce}$ (III) (Fig. 1.a and Fig. 1.b). The same behaviour is observed when P81R.Cy572 IL and P81R.D2EHPA IL were used (Fig. 1.c and Fig. 1.d). This extraction order is in accordance with the fact that the heavy rare earth elements (HREEs) are extracted before the light rare earth elements (LREEs), because of the existence of a characteristic diagonal relationship for REEs with the equilibrium $\mathrm{pH}$ (Swain and Otu, 2011). Moreover, the relationship between the extraction percentage and the ionic radii of the REE is inversely proportional (Mohammadi et al., 2015), so the charge density of $\mathrm{Ce}(\mathrm{III})$ is lower than that for $\mathrm{Eu}(\mathrm{III})$ and $Y(I I I)$.

The Y/Eu and Y/Ce selectivities are higher when using P81R·D2EHPA IL compared to using D2EHPA. For this reason, the P81R.D2EHPA IL was chosen to separate the yttrium from the Ce/Eu/Y mixture at equilibrium $\mathrm{pH}$ less than 0.3. In order to separate the europium from the remnant Eu/Ce solution mixture, the P81R.Cy572 IL at an equilibrium pH range of 0.5-1.5 was chosen, taking advantage of its higher selectivity value in comparison to the Cy572.
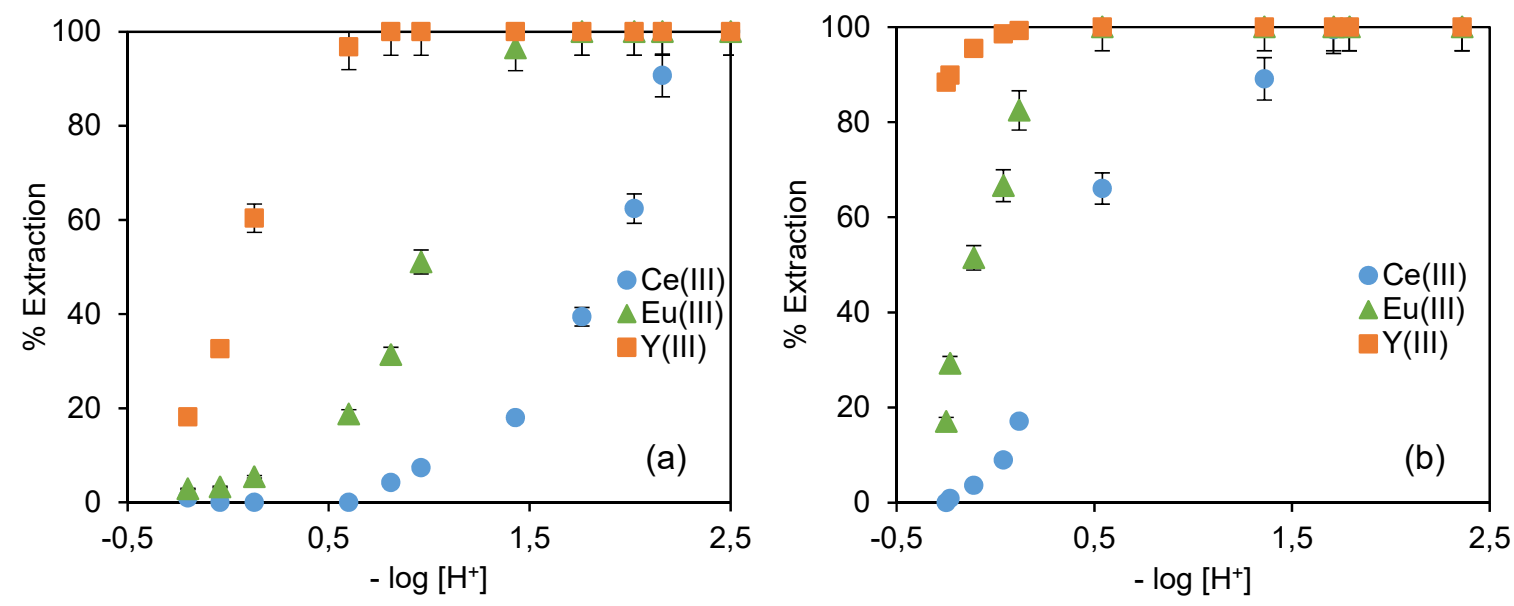

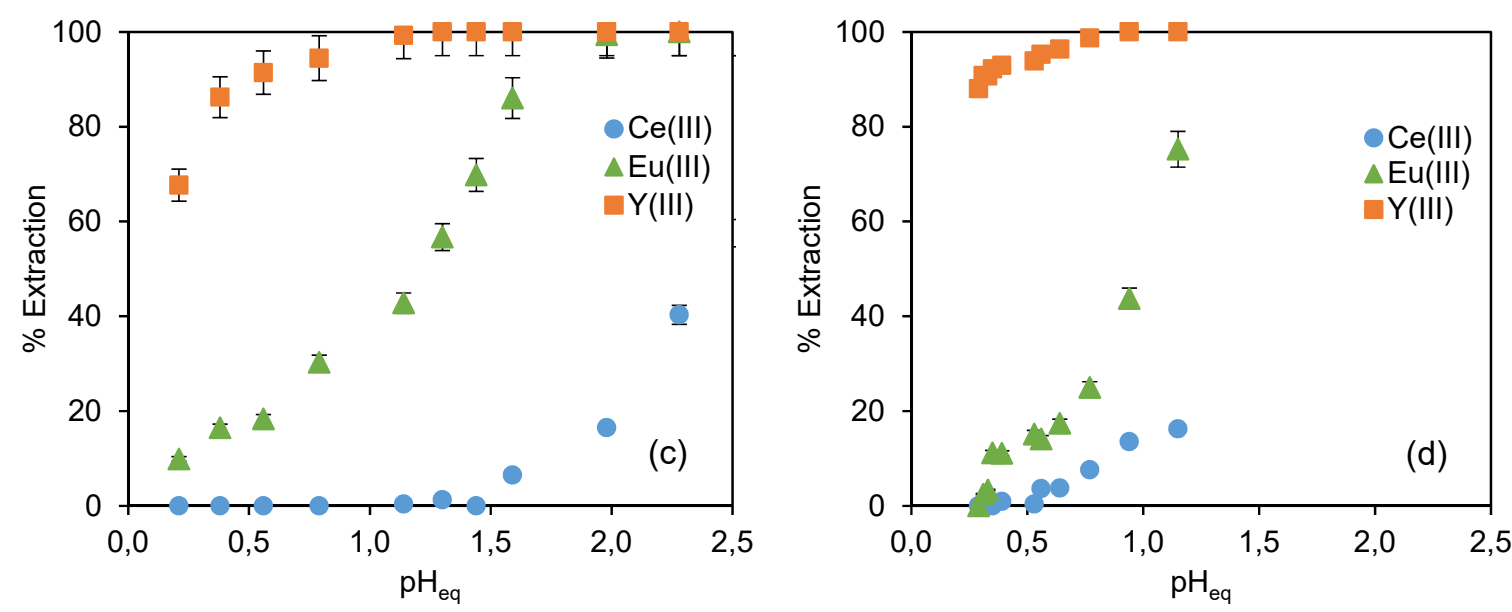

Fig. 1. Effect of equilibrium $\mathrm{pH}$ on the extraction of $1 \mathrm{~g} / \mathrm{L}$ of each rare earth in $4 \mathrm{~mol} / \mathrm{L} \mathrm{Cl}$. (a) Cy572 0.30 mol/L. (b) D2EHPA $0.30 \mathrm{~mol} / \mathrm{L}$. (c) P81R·Cy572 IL $0.30 \mathrm{~mol} / \mathrm{L}$. (d) P81R·D2EHPA IL $0.30 \mathrm{~mol} / \mathrm{L}$.

As is shown in Fig. 2.a, the results obtained plotting $\log D-3 \log \left[\overline{(H A}_{2}\right]$ vs. $-\log \left[H^{+}\right]$using Cy572 or D2EHPA $0.30 \mathrm{~mol} / \mathrm{L}$ are consistent with the suggested extraction mechanism in Eq. (7) due to the fact that the obtained slopes are about 3 for cerium, europium and yttrium. Hence, three protons are involved in the extraction process using cationic extractants such as Cy572 and D2EHPA in accordance with Pavón et al. (Pavón et al., 2018) and Tunsu et al. (Tunsu et al., 2016). However, the extraction mechanism, when ionic liquids such as P81R.Cy572 IL or P81R·D2EHPA IL are used, follows Eq. (8) mechanism, with no involved protons in it since there are not significant changes between the $\mathrm{pH}_{\text {initial }}$ and the $\mathrm{pH}_{\mathrm{eq}}$ as can be seen in Fig. 2.b.
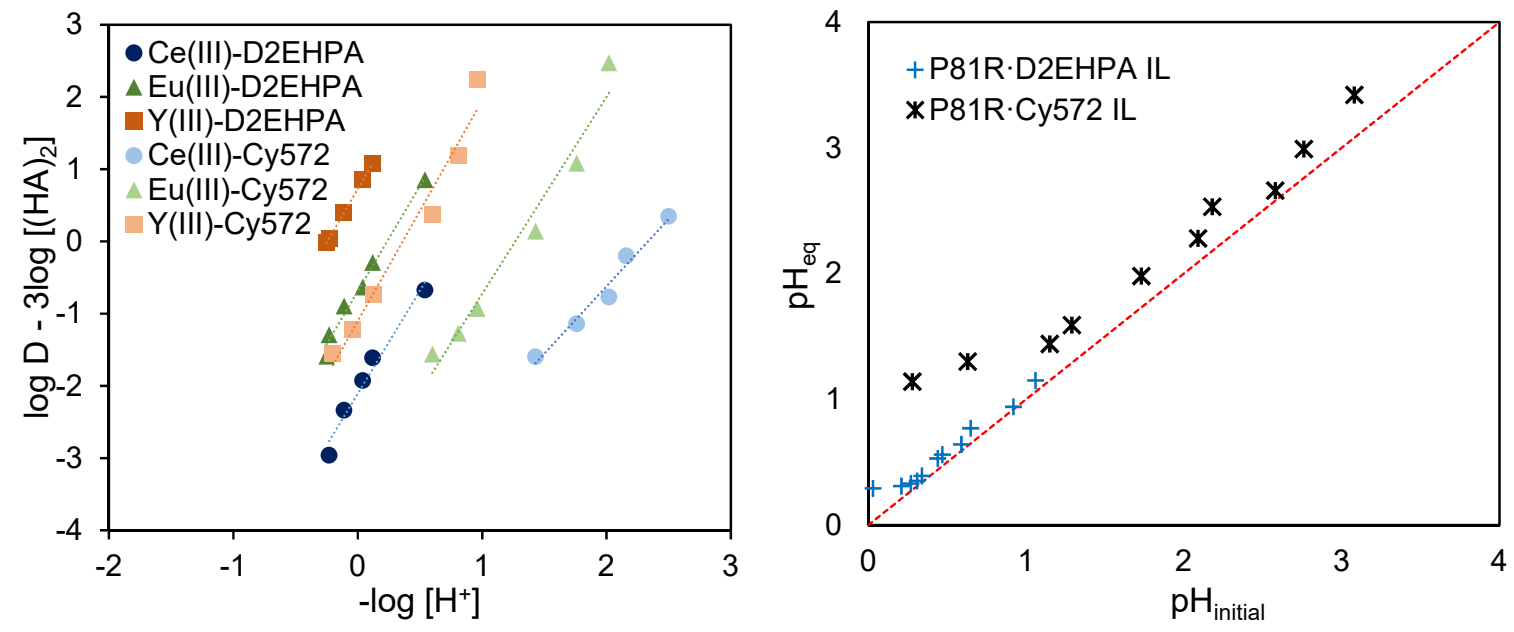

Fig. 2. Determination of the stoichiometric ratio of the extraction mechanism. (a) Plot of $\log \mathrm{D}-$ 
$3 \log \left[\overline{(\mathrm{HA})}_{2}\right]$ vs. $-\log \left[\mathrm{H}^{+}\right]$using Cy572 or D2EHPA $0.30 \mathrm{~mol} / \mathrm{L}$. (b) Variation of the pH during the REE extraction by using P81R·D2EHPA IL or P81R $\cdot$ Cy572 IL $0.30 \mathrm{~mol} / \mathrm{L}$.

\subsubsection{Effect of IL concentration}

To investigate the effect of the P81R·Cy572 IL and the P81R·D2EHPA IL concentration on the extraction of the $\mathrm{Ce} / \mathrm{Eu} / \mathrm{Y}$ mixture, the range of ILs concentration studied was 0.15 up to $0.60 \mathrm{~mol} / \mathrm{L}$. The aqueous phase solution contains $1 \mathrm{~g} / \mathrm{L}$ of each REE in $4 \mathrm{~mol} / \mathrm{L} \mathrm{Cl}$ medium and an initial $\mathrm{H}^{+}$concentration of 0.90 $\mathrm{mol} / \mathrm{L}$.

As expected, the percentages of extraction for $\mathrm{Ce}(\mathrm{III}), \mathrm{Eu}(\mathrm{III})$ and $\mathrm{Y}(\mathrm{III})$ increase when the ILs concentrations also increase as is shown in Fig. 3.
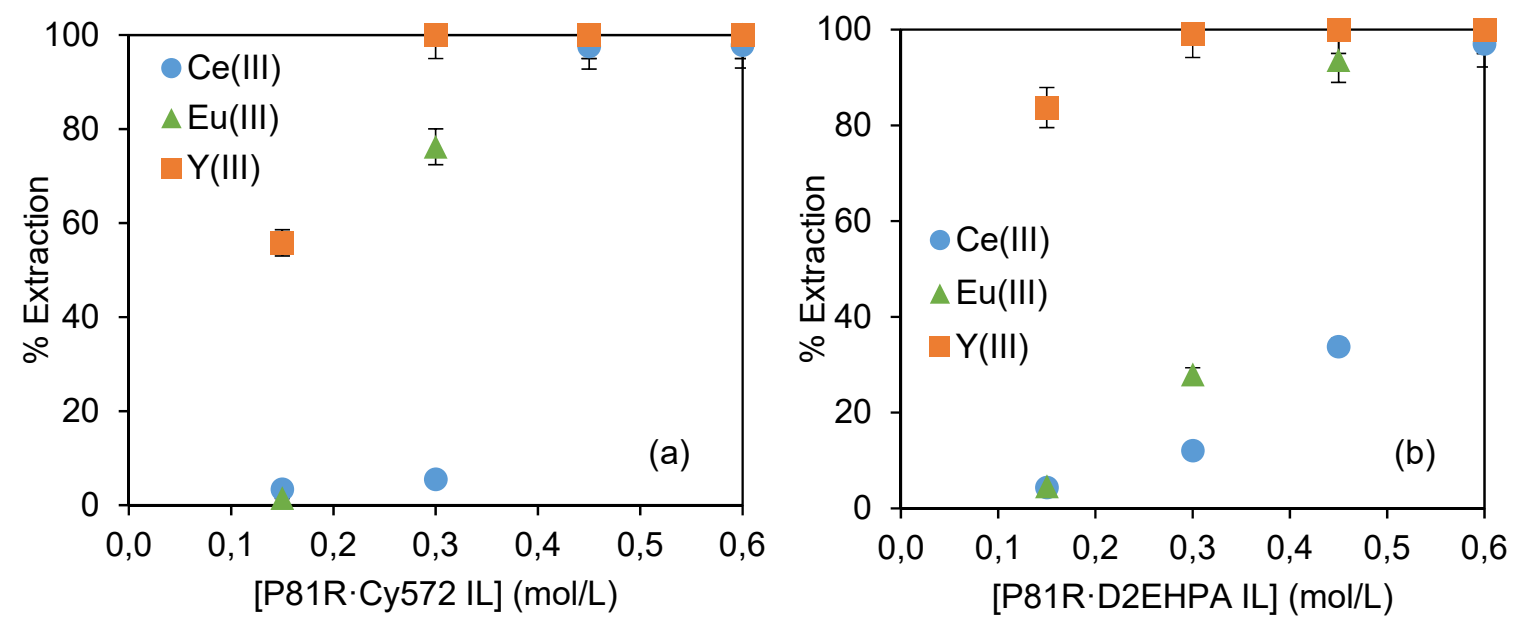

Fig. 3. Effect of ILs concentration on the extraction of $1 \mathrm{~g} / \mathrm{L}$ of each REE in $4 \mathrm{~mol} / \mathrm{L} \mathrm{Cl}$. (a) P81R.Cy572 IL (b) P81R·D2EHPA IL.

$\mathrm{Ce}(\mathrm{III}), \mathrm{Eu}(\mathrm{III})$ and $\mathrm{Y}(\mathrm{III})$ loaded in the organic phase can be stripped using $\mathrm{HCl} 4 \mathrm{~mol} / \mathrm{L}$, as can be seen in the results presented in Table 2, similar to the Padhan and Sarangi investigation in which Alamine 336. Cyanex $272 \mathrm{IL}$ is used as extractant to recover $\mathrm{Nd}$ and Pr from NdFeB magnets. These REEs could be completely stripped using a $\mathrm{H}_{2} \mathrm{SO}_{4}$ concentration higher than $2.16 \mathrm{~mol} / \mathrm{L}$ (Padhan and Sarangi, 2017). 
Table 2. Stripping yield of $\mathrm{Ce}(\mathrm{III}), \mathrm{Eu}(\mathrm{III}), \mathrm{Y}(\mathrm{III})$ from the loaded organic phases using $\mathrm{HCl} 4 \mathrm{~mol} / \mathrm{L}$.

\begin{tabular}{cccc|ccc}
\hline & \multicolumn{3}{c}{ P81R·Cy572 IL } & \multicolumn{3}{c}{ P81R·D2EHPA IL } \\
\hline [IL] (mol/L) & Ce & Eu & Y & Ce & Eu & Y \\
\hline $\mathbf{0 . 1 5}$ & 100 & 100 & 100 & 98 & 100 & 100 \\
$\mathbf{0 . 3 0}$ & 100 & 100 & 100 & 96 & 98 & 100 \\
$\mathbf{0 . 4 5}$ & 100 & 96 & 100 & 97 & 99 & 100 \\
$\mathbf{0 . 6 0}$ & 96 & 98 & 100 & 98 & 97 & 100 \\
\hline
\end{tabular}

For the Ce/Eu/Y separation using P81R.Cy572 IL or P81R·D2EHPA IL, the concentrations of 0.45 and $0.60 \mathrm{~mol} / \mathrm{L}$ can not be used, due to the high REEs extraction yields reached. According to the Table 3 , where the separation factors defined in Eq. (6) are shown, the most appropriate IL concentrations for this purpose are in the $0.15-0.30 \mathrm{~mol} / \mathrm{L}$ range. However, when $0.30 \mathrm{~mol} / \mathrm{L}$ of P81R.D2EHPA IL is used, the highest separation values are obtained, reaching 810 and 286 for $\beta_{Y / C e}$ and $\beta_{Y / E u}$, respectively. Although the $\beta_{\mathrm{Eu} / \mathrm{Ce}}$ obtained a value of 29 with $0.45 \mathrm{~mol} / \mathrm{L}$ using P81R.D2EHPA IL, which could be considered a good separation value, more amount of extractant would be required to increase it. Moreover, the highest $\mathrm{Eu} / \mathrm{Ce}$ selectivity value is achieved when $0.30 \mathrm{~mol} / \mathrm{L}$ of P81R.Cy572 IL is used.

Table 3. Separation factors for the Ce/Eu/Y mixture using different IL concentrations.

\begin{tabular}{cccc|ccc}
\hline & \multicolumn{3}{c}{ P81R·Cy572 IL } & \multicolumn{3}{c}{ P81R·D2EHPA IL } \\
\hline$[\mathrm{IL}](\mathbf{m o l} / \mathbf{L})$ & $\beta_{\mathrm{Y} / \mathrm{Ce}}$ & $\beta_{\mathrm{Y} / \mathrm{Eu}}$ & $\beta_{\text {Eu/Ce }}$ & $\beta_{\mathrm{Y} / \mathrm{Ce}}$ & $\beta_{\mathrm{Y} / \mathrm{Eu}}$ & $\beta_{\mathrm{Eu} / \mathrm{Ce}}$ \\
\hline $\mathbf{0 . 1 5}$ & 36 & 83 & 0.44 & 113 & 106 & 1.07 \\
$\mathbf{0 . 3 0}$ & $*$ & $*$ & 55 & 810 & 286 & 2.83 \\
$\mathbf{0 . 4 5}$ & $*$ & $*$ & $*$ & $*$ & $*$ & 29 \\
$\mathbf{0 . 6 0}$ & $*$ & $*$ & $*$ & $*$ & $*$ & $*$ \\
\hline
\end{tabular}

\section{${ }^{*} \beta$ not calculated because of the complete REE extraction}

\subsubsection{Stripping study}

The stripping study of cerium, europium and yttrium was carried out with different $\mathrm{HCl}$ concentrations. This acid stripping agent was chosen according to the stripping efficiency order: $\mathrm{HCl}>\mathrm{HNO}_{3}>\mathrm{H}_{2} \mathrm{SO}_{4}$ suggested by the Kuang et al. investigation (Kuang et al., 2017). 
The proposed stripping mechanism is shown in Eqs. (13)-(14). As can be seen, two steps to re-use the IL are required. Being the former one the stripping step with an acidic agent and a scrubbing step as the second one.

$$
\begin{aligned}
& 2 \overline{\mathrm{MeA}_{3} \cdot 3 \mathrm{RNH}_{3}^{+} \mathrm{Cl}^{-}}+6 \mathrm{H}^{+} \leftrightarrow 2 \mathrm{Me}^{3+}+3 \overline{(\mathrm{HA})_{2}}+6 \overline{\mathrm{RNH}_{3}^{+} \mathrm{Cl}^{-}} \\
& {\overline{(\mathrm{HA})_{2}}}_{2}+2 \overline{\mathrm{RNH}_{3}^{+} \mathrm{Cl}^{-}}+2 \mathrm{H}_{2} \mathrm{O} \leftrightarrow 2 \overline{\mathrm{RNH}_{3}^{+} A^{-}}+2 \mathrm{Cl}^{-}+2 \mathrm{H}_{3} \mathrm{O}^{+}
\end{aligned}
$$

The stripping study results using different concentrations of $\mathrm{HCl}$ are presented in Fig. 4. The REEs loaded in the organic phase, when $0.30 \mathrm{~mol} / \mathrm{L}$ of P81R. Cy572 IL was used, contained $0.05,0.76$ and $1 \mathrm{~g} / \mathrm{L}$ of $\mathrm{Ce}(\mathrm{III}), \mathrm{Eu}(\mathrm{III})$ and $\mathrm{Y}(\mathrm{III})$, respectively. In the case of P81R.D2EHPA IL $0.30 \mathrm{~mol} / \mathrm{L}, 0.12,0.28$ and $0.99 \mathrm{~g} / \mathrm{L}$ of $\mathrm{Ce}(\mathrm{III}), \mathrm{Eu}(\mathrm{III})$ and $\mathrm{Y}(\mathrm{III})$, respectively, were the concentrations loaded in the organic phase. The $\mathrm{H}^{+}$ initial concentration was $0.90 \mathrm{~mol} / \mathrm{L}$ and the phase ratio (A:O) was $1: 1$. Since the amount of $\mathrm{Ce}(\mathrm{III})$ extracted using this extractant concentration $(0.30 \mathrm{~mol} / \mathrm{L})$ is low $(\leq 12 \%)$ compared to the $\mathrm{Eu}(\mathrm{III})$ and $\mathrm{Y}(\mathrm{III})$ extracted, the stripping percentages of this metal are not included in Fig. 4.
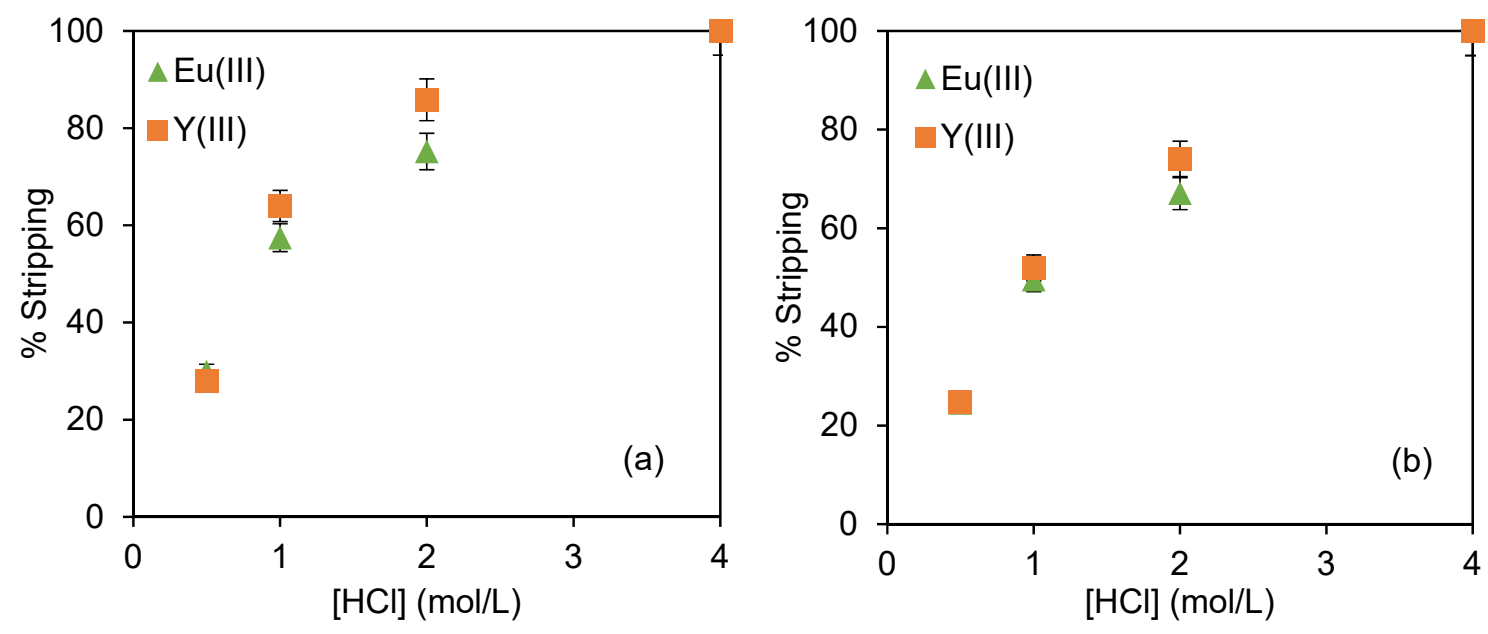

Fig. 4. Effect of the $\mathrm{HCl}$ concentration on the stripping of Eu/Y. (a) P81R.Cy572 IL $0.30 \mathrm{~mol} / \mathrm{L}$. (b) P81R·D2EHPA IL $0.30 \mathrm{~mol} / \mathrm{L}$.

Fig. 4 shows the plot of the stripping percentages of $\mathrm{Eu}(\mathrm{III})$ and $\mathrm{Y}(\mathrm{III})$ vs. the $\mathrm{HCl}$ concentration. As expected, their REE stripping percentages increase when the hydrochloric acid concentration also increases. However, comparing the stripping REE percentages obtained using P81R.Cy572 IL and P81R.D2EHPA IL, when the former is used, higher stripping REE percentages are obtained, as can be 
seen in Fig. 4.a. In the case of P81R.D2EHPA IL, a higher hydrochloric acid concentration is required to achieved the same percentage of stripping compared to P81R·Cy572 IL due to the bigger acidic character of P81R.D2EHPA IL. Using $4 \mathrm{~mol} / \mathrm{L}$ of $\mathrm{HCl}$, the stripping efficiency was $100 \%$ for both ionic liquid extractants.

\subsection{Cross-flow REEs separation process from a synthetic feed}

$\mathrm{Ce} / \mathrm{Eu} / \mathrm{Y}$ synthetic mixture contained $1 \mathrm{~g} / \mathrm{L}$ of each metal because it was the same concentration used in previous experiments. P81R·D2EHPA IL and P81R·Cy572 IL have been used to achieve the Ce(III), $\mathrm{Eu}(\mathrm{III})$ and $\mathrm{Y}(\mathrm{III})$ separation, since using a three stages cross-flow solvent extraction scheme allows us to recover each rare earth separately. The flow-sheet of the separation process is outlined in Fig. 5.

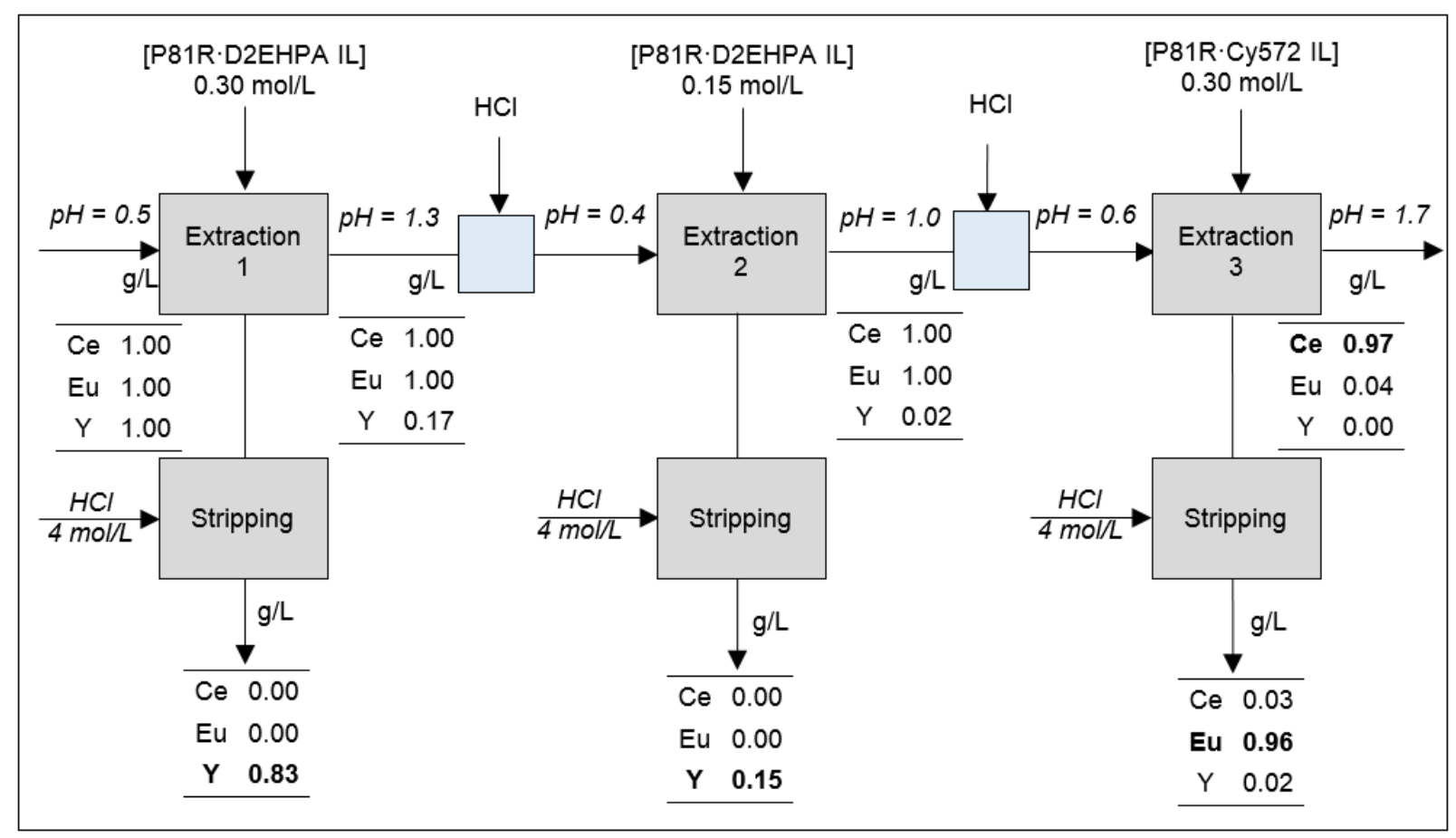

Fig. 5. Flow-sheet of the Ce/Eu/Y separation process using a three stages cross-flow solvent extraction. Aqueous phase: $1 \mathrm{~g} / \mathrm{L}$ of each metal in $4 \mathrm{~mol} / \mathrm{L} \mathrm{Cl}^{\circ}$. Organic phase: 0.30 and $0.15 \mathrm{~mol} / \mathrm{L}$ of P81R.D2EHPA IL in the first two stages and $0.30 \mathrm{~mol} / \mathrm{L}$ of P81R.Cy572 IL in the last stage. A:O ratio 1:1.

After the previously obtained results with a REEs mixture of $1 \mathrm{~g} / \mathrm{L}$, it was concluded that the P81R·D2EHPA IL allows obtaining higher separation values of $Y / E u$ and $Y / C e$. Once the yttrium is separated from the mixture, the europium and the cerium can be separated by using P81R·Cy572 IL. 
P81R.D2EHPA IL was used in the first two stages with concentrations of $0.30 \mathrm{~mol} / \mathrm{L}$ and $0.15 \mathrm{~mol} / \mathrm{L}$, respectively, to obtain $98 \%$ of the yttrium in the organic phase. In the second stage the concentration is reduced by half to avoid the $\mathrm{Ce}(\mathrm{III})$ and $\mathrm{Eu}(\mathrm{III})$ extraction. Cerium and europium were separated using $0.30 \mathrm{~mol} / \mathrm{L}$ of P81R.Cy572 IL in the third stage, obtaining $96 \%$ of the $\mathrm{Eu}(\mathrm{III})$ in the organic phase. Finally, $\mathrm{Eu}(\mathrm{III})$ and $\mathrm{Y}(\mathrm{III})$ were completely recovered from the organic phase using $4 \mathrm{~mol} / \mathrm{L}$ of $\mathrm{HCl}$ and $97 \%$ of the initial $\mathrm{Ce}$ (III) was obtained in the raffinate flow. Obviously, higher REEs concentrations in the stripping streams could be obtained by using lesser $A: O$ ratios.

\subsection{Cross-flow REES separation process from YOX leachate}

Once the Ce/Eu/Y separation was successfully achieved using a synthetic mixture of $1 \mathrm{~g} / \mathrm{L}$ of each REE, a new separation flow-sheet of these metals was proposed, adapted to the concentrations of $\mathrm{Ce}(\mathrm{III}), \mathrm{Eu}(\mathrm{III})$, $Y(I I I)$ found in the end-of-life fluorescent lamp wastes. After acid leaching of the sample, the REEs reach liquor contains $0.2,6.0$ and $8.5 \mathrm{~g} / \mathrm{L}$ of $\mathrm{Ce}(\mathrm{III}), \mathrm{Eu}(\mathrm{III})$ and $\mathrm{Y}(\mathrm{III})$, respectively. The concentration of these REEs are similar to the concentrations found by Tunsu et al. (Tunsu et al., 2014). However, in fluorescent lamps, more REEs such as gadolinium, terbium, dysprosium and lanthanum were identified, but their concentrations were less than $0.04 \mathrm{~g} / \mathrm{L}(0.04,0.03,0.01,0.03 \mathrm{~g} / \mathrm{L}$, respectively) and these metals were considered as trace metals.

Four stages were used to reach the REEs separation using P81R·D2EHPA IL and P81R·Cy572 IL, as shown in Fig. 6. An extra stage in the process using P81R.D2EHPA IL was required because of the high $\mathrm{Y}(\mathrm{III})$ concentration $(8.5 \mathrm{~g} / \mathrm{L})$ compared to the synthetic one $(1 \mathrm{~g} / \mathrm{L})$. The first three stages were necessary in order to obtain $98 \%$ of the yttrium in the organic phase using the P81R.D2EHPA IL. This IL was used at $0.30 \mathrm{~mol} / \mathrm{L}$ in the two first stages. However, $0.15 \mathrm{~mol} / \mathrm{L}$ was the concentration in the third stage, to avoid the Eu/Ce extraction. $\mathrm{Ce}(\mathrm{III})$ and $\mathrm{Eu}(\mathrm{III})$ were separated using $0.30 \mathrm{~mol} / \mathrm{L}$ of P81R.Cy572 IL in the last stage, obtaining $99.99 \%$ of $\mathrm{Eu}(\mathrm{III})$ in the organic phase. $4 \mathrm{~mol} / \mathrm{L}$ of $\mathrm{HCl}$ was enough to recover the $\mathrm{Eu}(\mathrm{III})$ and the $\mathrm{Y}(\mathrm{III})$ from the organic phases and $99.99 \%$ of $\mathrm{Ce}(\mathrm{III})$ was recovered in the raffinate flow. 


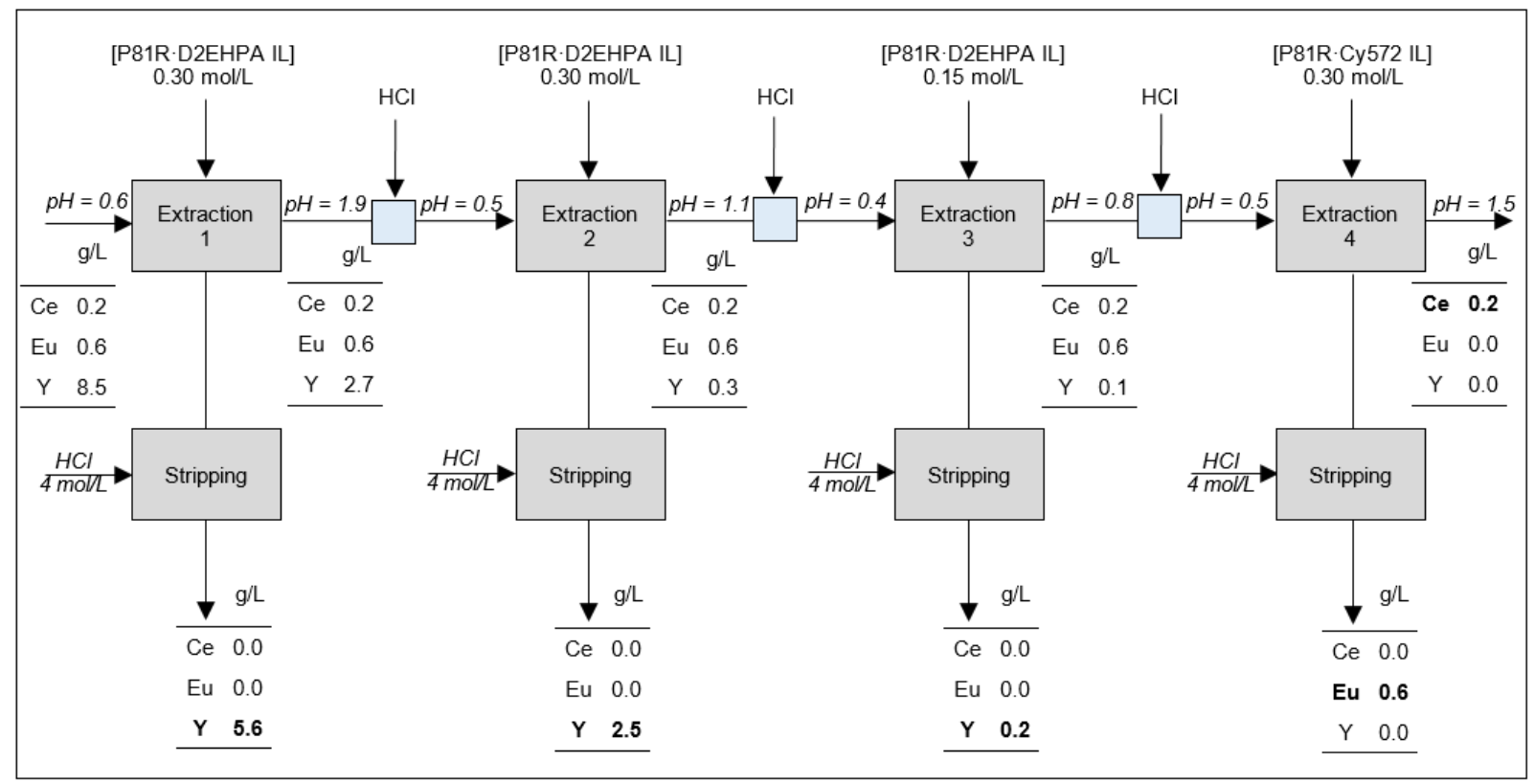

Fig. 6. Flow-sheet of the $\mathrm{Ce} / \mathrm{Eu} / \mathrm{Y}$ separation process using a four stages cross-flow solvent extraction. Aqueous phase: $0.2,0.6$ and $8.5 \mathrm{~g} / \mathrm{L}$ of $\mathrm{Ce}(\mathrm{III}), \mathrm{Eu}(\mathrm{III})$ and $\mathrm{Y}(\mathrm{III})$, respectively, in $4 \mathrm{~mol} / \mathrm{L} \mathrm{Cl}$. Organic phase: $0.30 \mathrm{~mol} / \mathrm{L}$ of P81R.D2EHPA IL in the first two stages, $0.15 \mathrm{~mol} / \mathrm{L}$ of P81R.D2EHPA IL in the third stage and $0.30 \mathrm{~mol} / \mathrm{L}$ of P81R.Cy572 IL in the last stage. A:O ratio 1:1.

\section{Conclusions}

The separation of REEs from a reach liquor from end-of-life fluorescent lamps was investigated in order to evaluate its recycling potential. This separation process that combines the use of P81R.D2EHPA IL and P81R.Cy572 IL as extractants allow us to obtain the individual metals of $\mathrm{Ce}(\mathrm{III}), \mathrm{Eu}(\mathrm{III})$ and Y(III) with purity $\geq 99.9 \%$. The loaded REEs from the organic phases were recovered using $4 \mathrm{~mol} / \mathrm{L}$ of $\mathrm{HCl}$.

After the systematic analysis of the effect of the parameters on the REEs extraction and successful application to a real waste stream from the fluorescent lamp waste, it can be concluded that $\mathrm{Ce}(\mathrm{III}), \mathrm{Eu}(\mathrm{III})$ and $Y(I I I)$ can be selectively recovered from their leachates using ionic liquid extractants from chloride media by a cross-flow solvent extraction process. 


\section{Acknowledgments}

This investigation was supported by the MINECO [grant number CTM2017-83581-R]. The authors would like to express their gratitude to Recyberica Ambiental S.L, Cytec Industries Inc. and Dow Chemical for providing free samples of fluorescent lamp wastes, Cyanex 572 and Primene 81R, respectively. 


\section{References}

Alguacil, F.J., Alonso, M., Lopez, F.A., Lopez-Delgado, A., Padilla, I., Tayibi, H., 2010. Pseudoemulsion based hollow fiber with strip dispersion pertraction of iron(III) using (PJMTH+)2(SO42-) ionic liquid as carrier. Chem. Eng. J. 157, 366-372. https://doi.org/10.1016/j.cej.2009.11.016

Belova, V. V., Voshkin, A.A., Kholkin, A.I., Payrtman, A.K., 2009. Solvent extraction of some lanthanides from chloride and nitrate solutions by binary extractants. Hydrometallurgy 97 , 198-203. https://doi.org/10.1016/j.hydromet.2009.03.004

Binnemans, K., Jones, P.T., Blanpain, B., Van Gerven, T., Yang, Y., Walton, A., Buchert, M., 2013. Recycling of rare earths: A critical review. J. Clean. Prod. 51, 1-22. https://doi.org/10.1016/j.jclepro.2012.12.037

Borai, E.H., Shahr El-Din, A.M., El-Sofany, E.A., Sakr, A.A., El-Sayed, G.O., 2014. Extraction and Separation of Some Naturally Occurring Radionuclides from Rare Earth Elements by Different Amines. Arab J. Nucl. Sci. Appl. 47, 48-60.

Coll, M.T., Fortuny, A., Kedari, C.S., Sastre, A.M., 2012. Studies on the extraction of Co(II) and $\mathrm{Ni}(\mathrm{II})$ from aqueous chloride solutions using Primene JMT-Cyanex272 ionic liquid extractant. Hydrometallurgy 125-126, 24-28. https://doi.org/10.1016/j.hydromet.2012.05.003

European Commission, 2009. A Consumer's Guide to Energy-Efficient Lighting.

European Union, 2009. Commission Regulation (EC) No 245/2009 of 18 March 2009. Off. J. Eur. Union OJ L76/17.

García-Díaz, I., López, F.A., Alguacil, F.J., 2017. Transport of indium(III) using pseudo-emulsion based hollow fiber strip dispersion with ionic liquid $\mathrm{RNH} 3+\mathrm{HSO} 4-$. Chem. Eng. Res. Des. 126, 134-141. https://doi.org/10.1016/j.cherd.2017.08.012 
Hasegawa, H., Begum, Z.A., Murase, R., Ishii, K., Sawai, H., Mashio, A.S., Maki, T., Rahman, I.M.M., 2018. Chelator-induced recovery of rare earths from end-of-life fluorescent lamps with the aid of mechano-chemical energy. Waste Manag. 80, 17-25.

https://doi.org/10.1016/j.wasman.2018.08.049

Innocenzi, V., Ippolito, N.M., De Michelis, I., Medici, F., Vegliò, F., 2016. A hydrometallurgical process for the recovery of terbium from fluorescent lamps: Experimental design, optimization of acid leaching process and process analysis. J. Environ. Manage. 184, 552559. https://doi.org/10.1016/j.jenvman.2016.10.026

Innocenzi, V., Ippolito, N.M., Pietrelli, L., Centofanti, M., Piga, L., Vegliò, F., 2017. Application of solvent extraction operation to recover rare earths from fluorescent lamps. J. Clean. Prod. 1-13. https://doi.org/10.1016/j.jclepro.2017.11.129

Ippolito, N.M., Innocenzi, V., De Michelis, I., Medici, F., Vegliò, F., 2017. Rare earth elements recovery from fluorescent lamps: A new thermal pretreatment to improve the efficiency of the hydrometallurgical process. J. Clean. Prod. 153, 287-298. https://doi.org/10.1016/j.jclepro.2017.03.195

Kuang, S., Zhang, Z., Li, Y., Wei, H., Liao, W., 2017. Synergistic extraction and separation of rare earths from chloride medium by the mixture of HEHAPP and D2EHPA. Hydrometallurgy 174, 78-83. https://doi.org/10.1016/j.hydromet.2017.09.011

Liu, Y., Jeon, H.S., Lee, M.S., 2015. Solvent extraction of Pr and Nd from chloride solutions using ternary extractant system of Cyanex 272, Alamine 336 and TBP. J. Ind. Eng. Chem. 31, 74-79. https://doi.org/10.1016/j.jiec.2015.06.009

Mishra, B.B., Devi, N., 2018. Solvent extraction and separation of europium (III) using a phosphonium ionic liquid and an organophosphorus extractant-A comparative study. J. Mol. Liq. 271, 389-396. https://doi.org/10.1016/j.molliq.2018.08.160 
Mohammadi, M., Forsberg, K., Kloo, L., Martinez De La Cruz, J., Rasmuson, Å., 2015.

Separation of $\mathrm{Nd}(\mathrm{III}), \mathrm{Dy}(\mathrm{III})$ and $\mathrm{Y}(\mathrm{III})$ by solvent extraction using D2EHPA and EHEHPA. Hydrometallurgy 156, 215-224. https://doi.org/10.1016/j.hydromet.2015.05.004

Padhan, E., Sarangi, K., 2017. Recovery of Nd and Pr from NdFeB magnet leachates with bifunctional ionic liquids based on Aliquat 336 and Cyanex 272. Hydrometallurgy 167, 134140. https://doi.org/10.1016/j.hydromet.2016.11.008

Pavón, S., Fortuny, A., Coll, M.T., Sastre, A.M., 2018. Neodymium recovery from NdFeB magnet wastes using Primene 81R Cyanex 572 IL by solvent extraction. J. Environ. Manage. 222, 359-367. https://doi.org/10.1016/j.jenvman.2018.05.054

Prodius, D., Mudring, A.V., 2018. Rare earth metal-containing ionic liquids. Coord. Chem. Rev. 363, 1-16. https://doi.org/10.1016/j.ccr.2018.02.004

Song, X., Chang, M.H., Pecht, M., 2013. Rare-earth elements in lighting and optical applications and their recycling. Jom 65, 1276-1282. https://doi.org/10.1007/s11837-013-0737-6

Su, X., Wang, Y., Guo, X., Dong, Y., Gao, Y., Sun, X., 2018. Recovery of Sm(III), Co(II) and $\mathrm{Cu}$ (II) from waste SmCo magnet by ionic liquid-based selective precipitation process. Waste Manag. 78, 992-1000. https://doi.org/10.1016/j.wasman.2018.07.004

Swain, B., Otu, E.O., 2011. Competitive extraction of lanthanides by solvent extraction using Cyanex 272: Analysis, classification and mechanism. Sep. Purif. Technol. 83, 82-90. https://doi.org/10.1016/j.seppur.2011.09.015

Tsamis, A., Coyne, M., 2015. Recovery of Rare Earths from Electronic wastes: An opportunity for High-Tech SMEs.

Tunsu, C., Ekberg, C., Retegan, T., 2014. Characterization and leaching of real fluorescent lamp waste for the recovery of rare earth metals and mercury. Hydrometallurgy 144-145, 91-98. https://doi.org/10.1016/j.hydromet.2014.01.019 
Tunsu, C., Lapp, J.B., Ekberg, C., Retegan, T., 2016. Selective separation of yttrium and europium using Cyanex 572 for applications in fluorescent lamp waste processing. Hydrometallurgy 166, 98-106. https://doi.org/10.1016/j.hydromet.2016.10.012

Zuo, Y., Chen, J., Li, D., 2008. Reversed micellar solubilization extraction and separation of thorium(IV) from rare earth(III) by primary amine N1923 in ionic liquid. Sep. Purif. Technol. 63, 684-690. https://doi.org/10.1016/j.seppur.2008.07.014 